\title{
Cause-effect chains in S-LCA based on DPSIR framework using Markov healthcare model: an application to "working hours" in Canada
}

\author{
Marwa B. Hannouf ${ }^{1}$ (D) $\cdot$ Getachew Assefa $^{1} \cdot$ Malek B. Hannouf $^{2} \cdot$ Ian $_{\text {Gates }}{ }^{3}$
}

Received: 16 October 2020 / Accepted: 23 March 2021 / Published online: 30 March 2021

(c) The Author(s) 2021

\begin{abstract}
Purpose This study has two aims: first, propose the use of the driver-pressure-state-impact-response (DPSIR) framework to expand the normal focus of impact pathways in social life cycle assessment (S-LCA) on endpoint impacts to a systematic analysis to find links between the main sources of social issues and impacts; second, develop a new impact assessment method to quantify the lifetime health and economic outcomes associated with social subcategories, for the first time, using decision analytic models.

Methods The DPSIR framework is mapped to the corresponding elements of the S-LCA context in relation to the social subcategories defined in the UNEP/SETAC methodological sheets. Next, a more robust approach is developed for causeimpact chains between social subcategories and impacts on human well-being based on decision-analytic models (decision trees and Markov models) using healthcare approaches and data. Finally, the health and economic consequences associated with social subcategories are quantified by using Quality Adjusted Life Years (QALYs) and costs based on medical literature and healthcare studies.

Results and discussion The method was applied to the "working hours" social subcategory in Canada. The cause-effect chain is built using DPSIR framework in relation to the current social issue in Canada of working more than standard hours. Results of the decision analytic model show that working standard hours is more effective and cost-saving than working more than standard hours from the Canadian healthcare perspective. Working standard hours compared to more than standard hours led to an increase of 0.73 QALY and decrease in cost of $\$ 6702$ per worker. Based on an estimated 2.4 million Canadian workers working more than standard hours, this resulted in a total gain of 1.7 million QALYs and saving of $\$ 16$ billion overall. Using cost-effectiveness analysis, possible interventions at multiple entry points of the cause-effect chain within DPSIR framework are proposed to reduce the negative health impacts and associated costs of working more than standard hours in Canada.

Conclusions Applying the method on other subcategories could help decision-makers establish the cause-effect aspects of the social performance of their product systems using a quantitative systematic analysis from a life cycle perspective. This approach supports corporate decision-makers to quantify social impacts associated with their product supply chains by calculating QALYs and healthcare costs of their socio-economic conditions enabling them to identify possible interventions to improve the social performance.
\end{abstract}

Keywords Social life cycle assessment · Cause-effect · Driver-pressure-state-impact-response · Quality-adjusted-life-years · Markov model $\cdot$ Working hours · Canada

\section{Introduction}

Social life cycle assessment (S-LCA) was the last tool to be developed within the framework of life cycle sustainability assessment (LCSA). While recognizing the importance of

Responsible editor: Marzia Traverso

Marwa B. Hannouf

mhannouf@ucalgary.ca

Extended author information available on the last page of the article integrating social impacts in life cycle assessment (LCA) started in the 1990s (O'Brien et al. 1996), there has been struggle to develop a standardized methodology for S-LCA (Huertas-Valdivia et al. 2020). A comprehensive overview 
of the history of S-LCA development can be found in Benoît et al. (2010) and Ramos Huarachi (2020). Essential improvements to integrate he social dimension in LCA were proposed by Dreyer et al. (2006) and Gauthier (2005). In 2009, guidelines for S-LCA were introduced by UNEP/SETAC, while developing S-LCA based on ISO 14,040 framework similar to Environmental life cycle assessment (E-LCA) (with a recent update of these guidelines in 2020, UNEP 2020). The new S-LCA guidelines provide step-by-step guidance on the application of S-LCA building on the developments in the area (UNEP 2020).

S-LCA is still considered under development (Zheng et al. 2020). Mapping the E-LCA to social aspects is not always suited and thus has resulted in disagreement on many points in S-LCA (Iofrida et al. 2019; Sureau et al. 2019). This divergence has resulted in the development of different methodological approaches in relation to the object of assessment, functional unit, system boundaries, data collection, impact assessment, etc. (e.g. Wu et al. 2014; Weidema 2018). Yet, S-LCA is still characterized by the life cycle scope and systematic process that differentiates this method from other methods assessing social aspects (UNEP 2020).

One of the main challenges in S-LCA is reaching a consensus on the evaluation and aggregation of social inventory data in the impact assessment phase (Hannouf and Assefa 2018). Two main types of impact assessment approaches exist based on UNEP SETAC (2009): types I and II. Type I consists of an evaluation of the data collected on social subcategories using performance reference points such as international conventions (Parent et al. 2010). Type II comprises an application of cause-effect chains to understand the causal associations between inventory indicators and midpoint or endpoint categories (Parent et al. 2010). Since the publication of S-LCA guidelines and associated methodological sheets (UNEP/SETAC 2009, 2013), Type I social life cycle impact assessment (S-LCIA) is being used to a greater extent (Sureau et al. 2019). Parallel to this, type II impact pathway approaches continued developing in different directions despite challenges (e.g., Arvidsson et al. 2018; Neugebauer et al. 2017; Iofrida et al. 2019). The main challenge in building cause-effect chains in type II S-LCIA is mainly because impacts pathways cannot be described in the same way as E-LCA with the different nature of connections and scientific disciplines involved (Sureau et al. 2019; Iofrida et al. 2019; Zheng et al. 2020). E-LCA builds on physical and natural disciplines with quantitative data whereas S-LCA is directly connected to the social sciences with qualitative data which often poses the difficulty in mapping and validating the causality chains in S-LCA (Sureau et al. 2019; Iofrida et al. 2019).

Among the different classifications proposed for the approaches in type II S-LCIA (e.g., Macombe 2013; Wu et al. 2014; Neugebauer 2016), a recent study by Sureau et al.
(2019) has classified the approaches into three types: (1) identifying or proposing indicators for pathways or general frameworks, (2) investigating/testing empirically existing impact pathways, (3) and applying and quantifying impact pathways in case studies. As concluded by Sureau et al. (2019) in their review, existing type II S-LCIA approaches miss the main point of impact pathways examining the connections between the main root causes of social issues and impacts. Most approaches focus on accounting endpoint impacts without the chain of effects leading to those impacts (Sureau et al. 2019). Reporting only on endpoint impacts does not allow awareness of the problems' sources and thus, can result in missing improvement potentials for the social performance of product systems. Therefore, it is crucial to expand system boundaries of current impact pathways to a more systematic approach, investigating the links between main sources of social issues and impacts thereby identifying underlying causes at different points in the cause-effect chain and providing multiple entry points for intervention. This expansion will thus help to achieve the aim of S-LCA to support decision-makers to develop effective solutions that improve the social performance of product systems (UNEP/ SETAC 2009).

Furthermore, another challenge in current type II S-LCIA approaches is the focus on impacts at macro-level scale; for example, the impact of gross domestic product per capita or income inequality on life expectancy or child mortality rate (Feschet et al. 2012; Bocoum et al. 2015) or productivity impact of missing governance (Weidema 2018). These approaches use a top-down approach thus missing many social variables (i.e., subcategories such as those related to working conditions: e.g., discrimination, working hours, fair salary) tackled in type I S-LCIA (Sureau et al. 2019). Quantifying macro-level scale impacts is associated with availability to relatively easy data access at macro-level (Sureau et al. 2019). However, evaluating the impacts on social subcategories can be considered relatively challenging due to difficult data access that are long-term and thus are associated with uncertainty. Therefore, there is a need for a decision-analytic model to assess long-term uncertain outcomes associated with social subcategories in cause-effect chains to inform decision-makers on possible interventions. Decision-analytic modelling is a systematic approach gener- $=$ ally considered a critical part of healthcare policy to inform decisions with uncertainty in economic evaluations of pharmaceuticals and other healthcare technologies (Siebert 2003) as well as comparison of outcomes of multiple strategies after assessing all related health impacts (i.e., quality of life and survival) and costs over time (Siebert 2003).

In this study, the two main challenges addressed are as follows. First, the connections between the main sources of social issues and impacts in cause-effect chains in S-LCA are explored by using the driver-pressure-state-impact-response 
(DPSIR) framework. This framework goes beyond the normal focus of impact pathways in S-LCA on endpoint impacts to a systematic analysis by understanding the sources of problems and thus identify effective possible improvements targeting causes at different levels in cause-effect chains. The framework extends the impact pathways of type II S-LCIA using a bottom-up approach to include a larger variety of social variables addressed in type I of S-LCIA covering for the first time the list of social subcategories in UNEP/SETAC S-LCA methodological sheets. Second, the lifetime health and economic outcomes associated with social subcategories will be quantified by developing a more robust impact pathway method building on Weidema (2006) using decision analytic models including decision trees and Markov models.

\section{Methods}

The method described here has two steps. First, the components of DPSIR framework are mapped into its S-LCA equivalents to build relationships surrounding cause-effect chains in S-LCA. Second, a new impact assessment method based on decision trees and Markov models is developed to evaluate and quantify the life-time health and economic outcomes associated with social subcategories.

\subsection{Mapping DPSIR framework to S-LCA context}

\subsubsection{Background}

The DPSIR framework, established by the European Environmental Agency (EEA) in 1999, has been widely used to model environmental problems (Smeets and Weterings 1999). The framework establishes cause-effect relationships between socio-economic and natural systems by integrating knowledge across disciplines organizing socio-ecological problems through their origins and consequences of these problems to help identify solutions. DPSIR has been widely used to assess and manage environmental related problems. However, its application outside the environmental arena is limited. Hannouf and Assefa (2017) applied DPSIR within life cycle sustainability assessment (LCSA) to represent cause-effect relationships between the three dimensions of sustainability in environmental problems. More recently, Weidema (2020) used DPSIR to provide a taxonomy for social impact pathway indicators. They structured the socioeconomic indicators in LCA between three categories in DPSIR framework: pressure indicators, midpoint impact and endpoint impact indicators. The taxonomy was solely based on quantifiable indicators while verifying the impact pathways through input-output balances (Weidema 2020). But their study has not used the UNEP/SETAC (2013) based social subcategories.

The use of DPSIR extends cause-effect chains beyond the current focus of approaches in type II S-LCIA on latter parts (impacts of social issues) to the early parts of the chains by investigating connections between causes and impacts of social issues. Therefore, in this study, DPSIR is applied to establish the cause-effect chains in S-LCA in relation to UNEP/SETAC social subcategories, linking the root causes of social issues to the impacts. This holistic analysis that looks at both the upstream (causes) and downstream (impacts) sides of impact pathways can consequently derive multiple entry points for improvement potentials of the social performance of product systems.

\subsubsection{Application of DPSIR in S-LCA context}

Social problems do not operate in the same way as environmental ones and mapping DPSIR must be adjusted to a social context. Figure 1 presents these components and connections. Socio-economic and industrial activities function as human drivers ( $\mathrm{D}=$ driver) that increase or mitigate socioeconomic pressures on stakeholder groups through employment conditions and investments in stakeholders' health and well-being conditions ( $\mathrm{P}=$ pressure). These socio-economic pressures change the state of social conditions of stakeholder

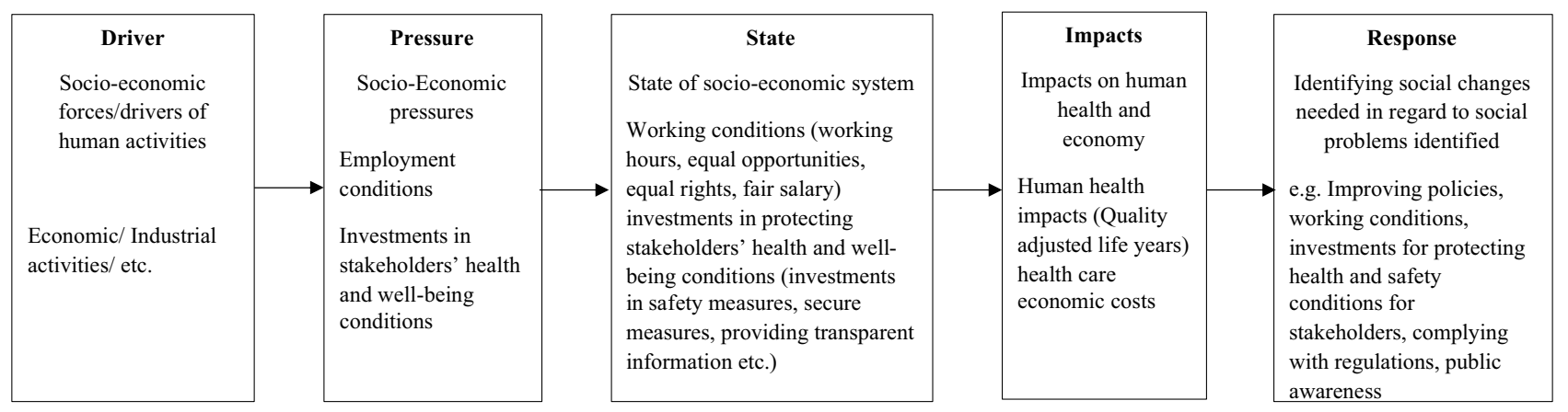

Fig.1 Mapping DPSIR framework into S-LCA context 


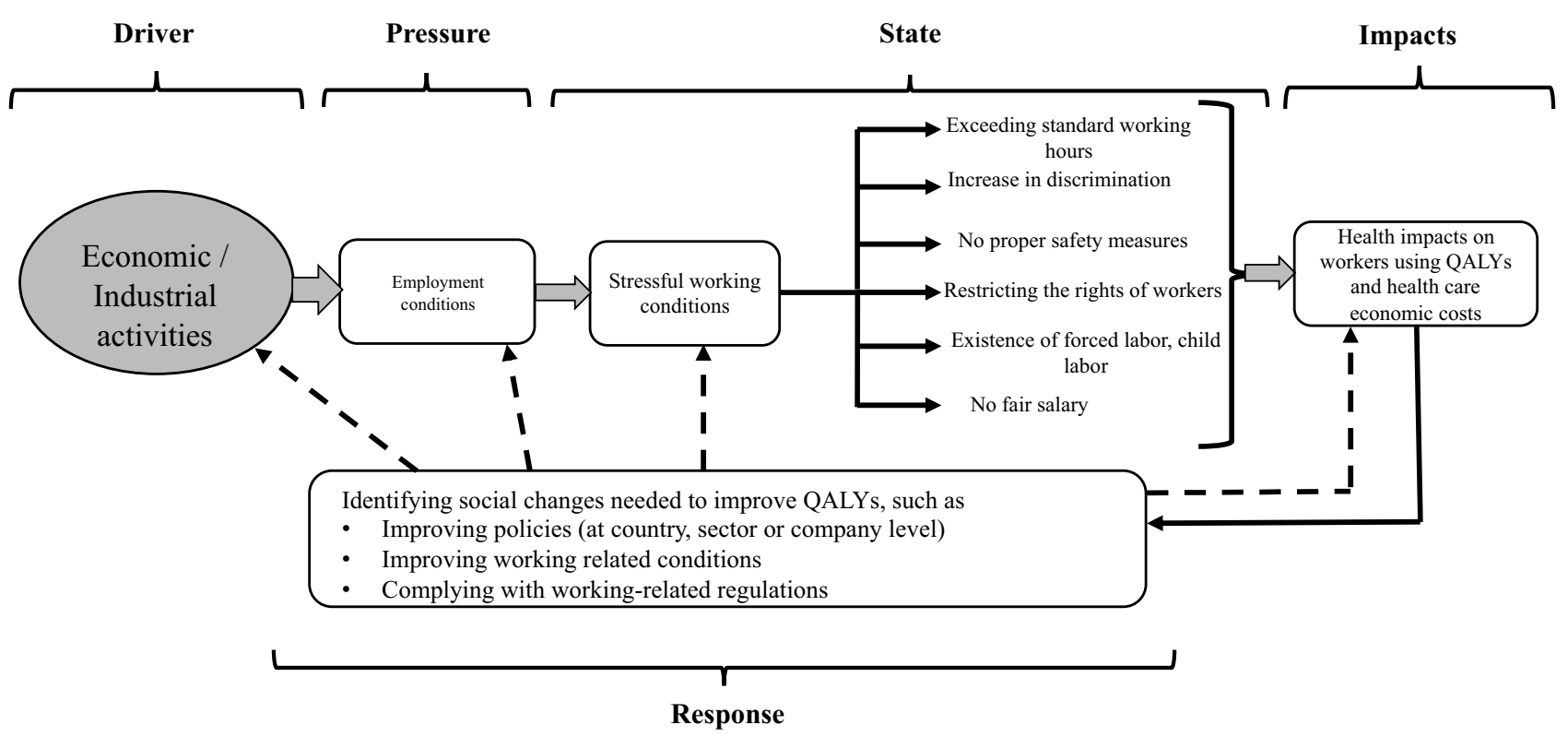

Fig. 2 Relevant subcategories for "workers" stakeholder group with direct connections within DPSIR

groups ( $\mathrm{S}=$ state). Social conditions are defined as the social subcategories related to stakeholder groups presented in the UNEP/SETAC methodological sheets. We identified the relevant stakeholder groups and associated subcategories for use in DPSIR, where direct connections can be built between social conditions and health impacts. These connections refer to social conditions that can potentially expose stakeholder groups to the risk of health impacts that in turn can be translated to economic consequences. Three stakeholder groups are found relevant: workers, local community, and consumers (see Online Resource for a complete list of relevant subcategories and stakeholder groups with developed connections). Figure 2 presents an example of the relevant social subcategories for "workers" stakeholder group and direct connections within DPSIR. The state of social conditions depends on organizations' decisions (e.g., on working conditions; investments in measures protecting consumers' health) and should be collected for each case, when building cause-effect chains. This has been used in type I S-LCIA methods where social impacts are tied to companies' performance and not to a quantified amount of functional unit (Ramirez et al. 2014, 2016; Petti et al. 2016; Hannouf and Assefa 2018). Thus, the results represent the social performance of companies responsible for different unit processes of product systems. An example for data to be collected for the "workers" stakeholder group social subcategories is listed in Table 1. The data can be collected at company, sector, or country level depending on the goal and scope of the specific study.

A change of the state of social conditions (such as changing working conditions and investments in safety measures) results in impacts on human health (quantified by the change in quality adjusted life years (QALYs)) and healthcare economic costs ( $\mathrm{I}=$ impacts). An impact assessment method to
Table 1 Example of inventory data to be collected for the "workers" stakeholder group social subcategory to define state of social conditions

\begin{tabular}{ll}
\hline Social subcategories & Examples of data (collected at company, sector, country level) \\
\hline Working hours & Number of workers working more than standard hours \\
Discrimination/equal opportunities & Number of workers affected by discrimination \\
Health and safety & Number of workers affected by non-safety measures \\
Social benefits/social security & Number of workers affected by restriction of rights (not pro- \\
& viding social benefits) \\
Freedom of association and collective & Number of workers affected by restriction of rights (not pro- \\
bargaining & viding freedom of association) \\
Child labor & Number of children working \\
Forced labor & Number of workers affected by forced labor \\
Fair salary & Number of workers with no fair salary \\
\hline
\end{tabular}


measure these impacts is described in Sect. 2.2. Systematic analysis identifies the response $(\mathrm{R})$ needed to deal with the social issues defined. Social changes may occur via compliance with existing policies, initiating new policies, improving current working conditions, and/or investments in health and safety of stakeholders etc. These responses affect each DPSIR process in turn by changing social conditions, reducing impacts, and affecting drivers and pressures.

\subsection{Impact assessment method based on decision-analytic models: decision trees and Markov model}

\subsubsection{Comparison with previous methods}

The impact assessment method developed here is based on the concept that negative socio-economic conditions (related to social subcategories) impact people's health (Weidema 2006) and thus raise costs for healthcare. Health impacts represent all possible health consequences of the exposure to socio-economic conditions and are determined based on medical health literature investigating the association between social conditions and health aspects (e.g., Wong et al. 2019). Health impacts are quantified then in terms of the increase or decrease of the QALYs.

The present method is inspired by Weidema (2006) where impact chains connecting social aspects to impacts on human well-being and productivity, use the concept of QALYs. Whereas Weidema (2006) estimates short-term and long-term QALYs associated with each social aspect by assuming their health equivalents, the method described here uses evidence and approaches from healthcare studies to identify health states associated with each social issue. The QALYs of each health state is quantified by modeling life-time results using a Markov healthcare model. Iofrida et al. (2019) assessed the health impacts on workers affected by specific working conditions (e.g., work pressure, exposure to chemicals) estimated from tasks and health aspects are associated with each working condition. Iofrida et al. (2019) do not aggregate the results in the form of QALYs, do not use the list of UNEP/SETAC social subcategories and do not model the lifetime health impacts and resulting costs. The method developed here goes beyond previous approaches by modeling the lifetime health impacts measured in QALYs with economic costs in estimating consequences in relation to social subcategories based on medical literature and healthcare studies.

\subsubsection{Impact assessment method description}

The purpose is to guide optimal decision-making in comparing the lifetime impact of the existing state of social condition in relation to the subcategory for each case to another alternative state by combining the health and economic impacts. Decision trees and Markov models are used in this study instead of more complex dynamical models (Siebert 2003). A schematic representation of the impact assessment method steps is presented in Fig. 3. To collect data in relation to these steps, a literature review is conducted on medical studies and secondary sources. Looking at different types of medical studies, cohort studies are the most effective means to study the association between causes and effects (Mann 2003). Cohort studies look at two cohorts of a specific population exposed and un-exposed to a specific intervention, and follow-up on these cohorts for a period of time retrospectively or prospectively assessing the development of different health outcomes. Cross-sectional studies and case control studies are excluded since they measure the causes and effects at a specific point of time and not in temporal sequence, which does not prove rigorously the association between causes and effects (Mann 2003). In conducting this literature review, a focus is given to those related to the geographical area of the specific case study.

A decision tree is built to link social conditions and possible health consequences of experiencing different social conditions based on medical health literature. The analysis has a lifetime horizon and thus a Markov model is used to project the lifetime health and economic consequences of an average age population going through each condition (Siebert 2003). A schematic representation of both decision tree and Markov model structure are presented in Online Resource. Health states (e.g., anxiety, stress, metabolic syndrome) are used to represent all possible health consequences of the exposure to socio-economic conditions. In Markov model (schematic representation presented in Online Resource), individuals move from the major health states to the death state as their conditions evolve over time. This time is considered a discrete time period called a "cycle." Movements from a healthy state to a negative health state or to the death state are represented as "transition probabilities." Time spent in each health state for each cycle is associated with a health utility score (utility scores describe the quality of life in a certain health state where perfect health is valued 1 and death 0 ) and a cost. For each social condition, the expected average QALY and healthcare cost is calculated as a weighted average of all possible outcomes, using the probabilities as weights, and then results are compared between the social conditions. QALYs is the product of both morbidity (measuring the quality of life (utility score)) and mortality (measuring the length of life (time spent in each health state)).

By running the Markov model for the lifetime using TreeAge Software (Tree-Age Software, Inc.), the lifetime QALYs and healthcare costs of an average person undergoing each social condition are calculated. Next, the results for the total population under each condition of the specific 


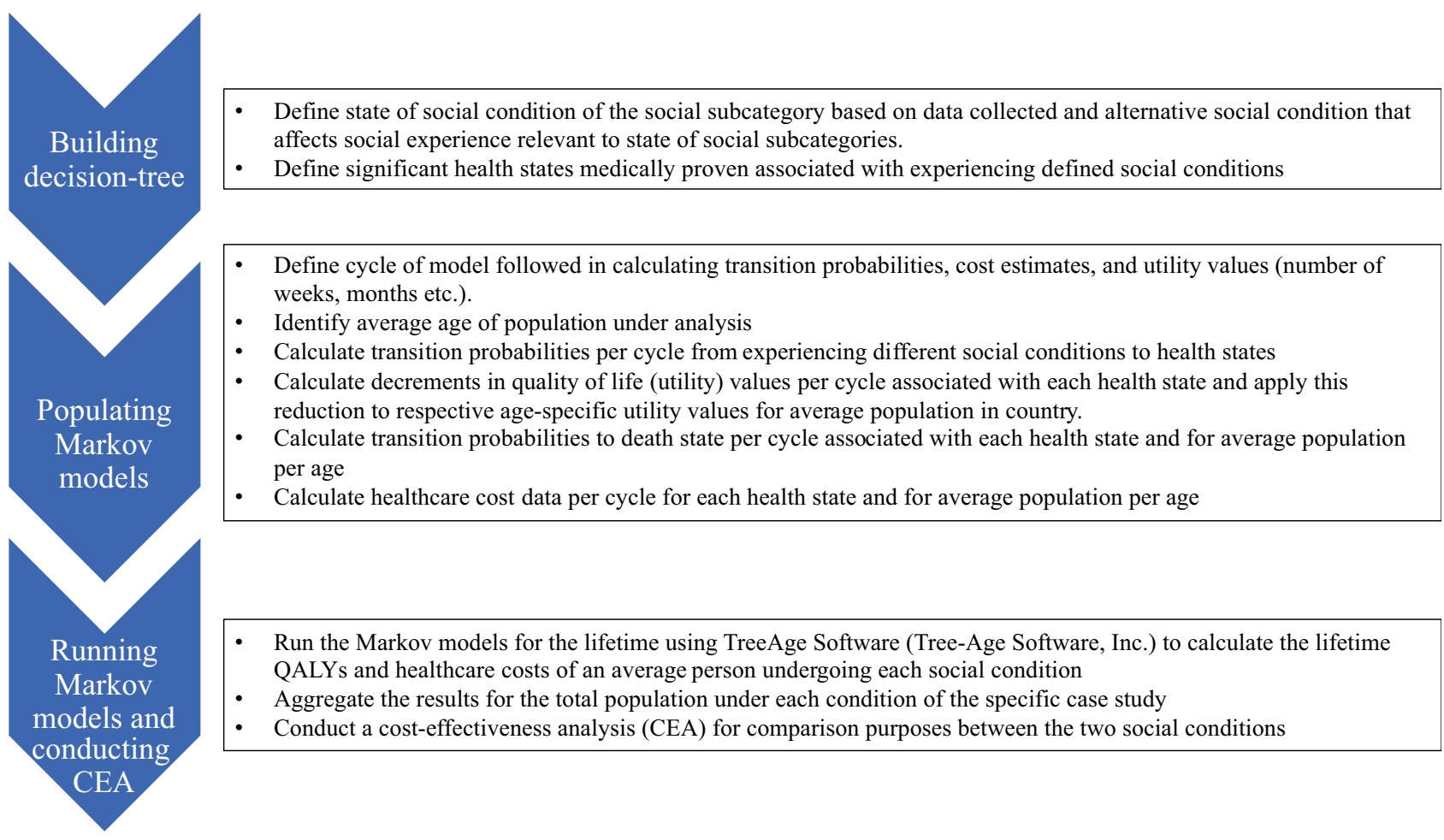

Fig. 3 Schematic representation of impact assessment method steps

case study are aggregated and a cost-effectiveness analysis (CEA) for comparison purposes between the two social conditions is conducted. CEA produces a more robust and meaningful outcome measure by combining the quality and quantity of the outcomes (Torrance 1986). CEA is usually used as a formal framework in healthcare systems to review medical technologies and inform health technology adoption decisions through a comparison of the incremental costs and incremental benefits associated with incorporating a new medical technology into an existing standard of care (Clement et al. 2009). It is used by the National Institutes for Health and Clinical Excellence (NICE) in the United Kingdom (UK) (Miners et al. 2005) and the Pharmaceutical Benefits Advisory Committee (PBAC) in Australia (Henry et al. 2005). CEA is adopted here to compare costs and benefits of multiple social conditions.

Figure 4 presents an example of CEA between current social condition and two alternative new social conditions. By applying CEA, an alternative new social condition may be associated with an additional cost $\left(\mathrm{N}_{1}\right.$ in Fig. 4) which is then considered "cost-effective" based on a value judgment (what cost is considered a good price for an additional outcome "QALY") (Garber and Phelps 1997). In medical literature, several heuristics are commonly used to assist in making this value judgment such as a comparison with pre-specified thresholds (Devlin and Parkin 2004; Laupacis 2006). In this case, the results of a CEA are usually presented in the form of a ratio called the incremental cost-effectiveness ratio (ICER) which is associated with incorporating a new medical technology. We are adopting ICER to our method:

$$
\text { ICER }=\frac{\text { Cost }_{\text {New }}-\text { Cost }_{\text {Current }}}{\text { Health }_{\text {New }}-\text { Health }_{\text {Current }}}
$$

where Cost $_{\mathrm{New}}$ is the total cost of the alternative new social condition, Cost ${ }_{\text {Current }}$ is the total cost of current social



Fig. 4 Example of cost-effectiveness analysis between current social condition and two alternative new social conditions (C: current social condition; $\mathrm{N}_{1}$ : 1st new alternative social condition; $\mathrm{N}_{2}$ : 2 nd new alternative social condition) 
condition, Health $\mathrm{New}_{\mathrm{New}}$ is the total QALYs associated with the alternative new social condition, and Health $\mathrm{Current}_{\text {is }}$ the total QALYs associated with the current social condition. In other cases, the alternative new social condition may be associated with a saving of cost $\left(\mathrm{N}_{2}\right.$ in Fig. 4). In that case, this social condition would be considered as cost saving and more effective at the same time. The results of the CEA within DPSIR will then guide decision-making in developing possible cost-effective interventions to reduce the negative impacts of socio-economic states.

\section{Case study: cause-impact chains in relation to "working hours" in Canada}

\subsection{Application of method}

To illustrate the application of the method, we are using the example of "working hours" social subcategory in Canada. Working hours in Canada is defined as working $40 \mathrm{~h}$ per week (Government of Canada 2020). Inventory data collected for working hours shows that around 2.4 million workers in Canada work more than $40 \mathrm{~h}$ per week (Statista 2020a). Using this information, we establish the cause-impact chain in relation to "working hours" subcategory based on DPSIR, as shown in Fig. 5. The established impact pathway connects the root causes of the existing social issue in Canada of working more than standard hours to the impacts.

Socio-economic and industrial activities (D) increase socio-economic pressures on workers through their employment conditions $(\mathrm{P})$. This is due to the main objective of companies as profit maximization and reduction of costs. These socio-economic pressures change the state of the social conditions for workers stakeholder group into stressful conditions by exceeding the number of standard working hours (S). Changing this state causes health impacts on workers quantified using QALYs and thus, healthcare economic cost impacts (I). This systematic analysis identifies effective responses $(\mathrm{R})$ in the form of social changes needed to improve QALY such as improving policies, improving current working conditions, and complying with existing working-related regulations.

The decision analytic model is used to project the lifetime health and economic consequences of the current state of social issue in Canada in relation to "working hours" subcategory (working more than standard hours) compared to the alternative state of working standard hours. The purpose is to compare the results of the two social conditions in the form of lifetime QALYs and resulting healthcare economic costs and thus guide decision making in developing interventions that can reduce the negative impacts of the current socio-economic situation in a cost-effective way.

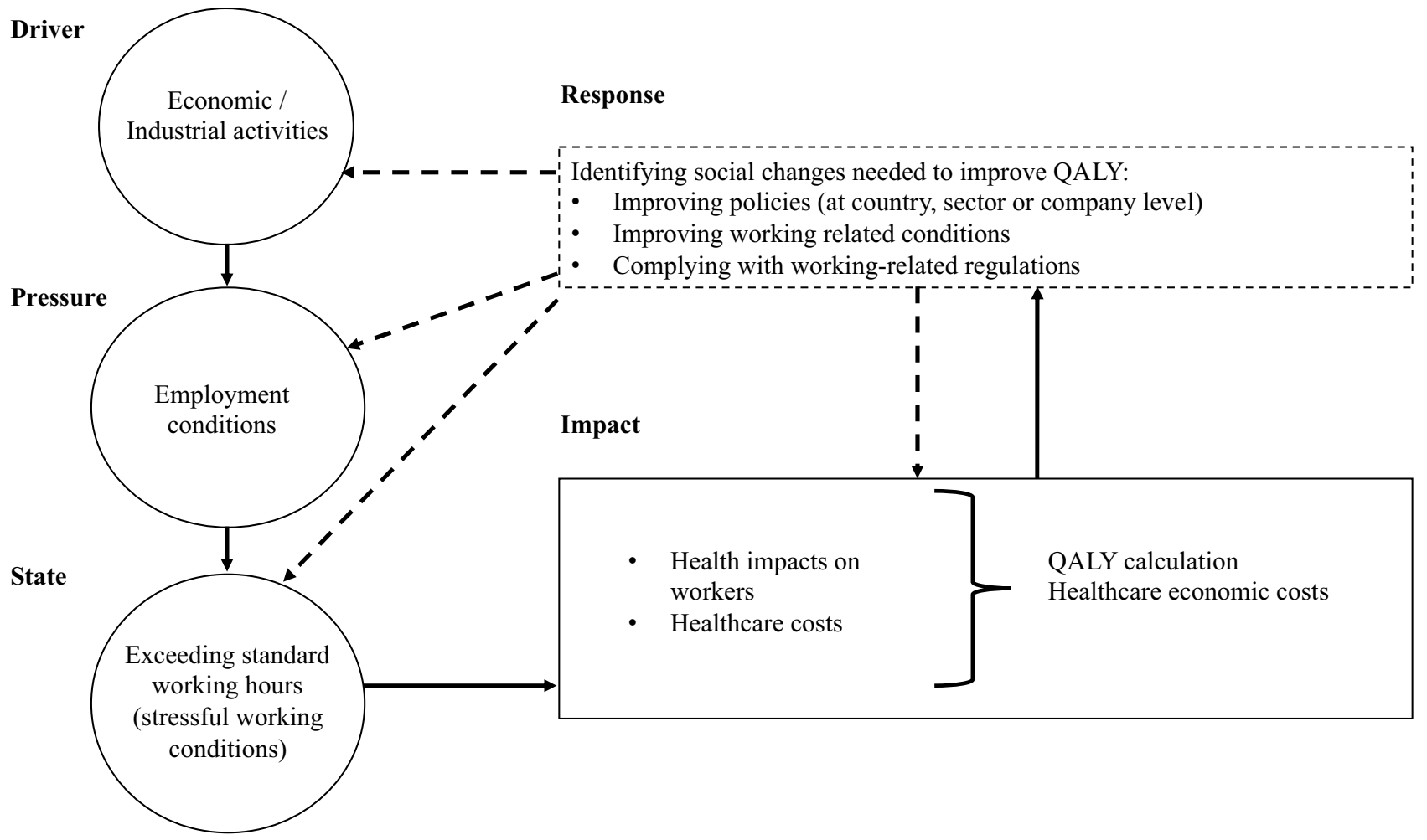

Fig. 5 DPSIR framework, illustration using “working hours" social subcategory 
The model begins with a definition of two working hours conditions: (1) employing "standard working hours" (i.e., defined in Canada as working for $40 \mathrm{~h} /$ week) or (2) "more than standard working hours" (i.e., > $40 \mathrm{~h} /$ week). Each condition is followed by a Markov model, which is used to project the lifetime health and economic consequences of an average age hypothetical cohort of workforce undergoing each working condition in Canada. We looked at the distribution of workforce ages in Canada (Statista 2020b) and calculated the average age of workforce as 37 years. The cycle used in the model for this case study is defined as one year. A literature review is conducted to populate each Markov model. The five steps of literature review are described in Table 2.

A detailed explanation of all data collected, transition probabilities, death probabilities, utility values, and cost estimates is presented in Online Resource. Each Markov model simulated yearly probability transitions among the following eight major distinct health states that are medically proved to be associated with working hours: (1) healthy unaffected by working hours, (2) cardiovascular heart (CVH) disease, (3) depression, (4) sleep disturbance, (5) anxiety, (6) mental health disorders, (7) injury, and (8) death (see Fig. 6). A definition for these health states is presented in Online Resource. The two Markov models differed from each other in that they carried different risks of these major health complications that are associated with different working hours conditions. Since it is assumed that there is no intervention during the lifetime of the models, workers who make a transition to any of the health states remain in that state unless they die.

The analysis was conducted from the Canadian healthcare payer's perspective. We applied a discount rate of $1.5 \%$ per annum to costs and QALYs following recommendations by the Canadian Agency for Drugs and Technologies in Health (CADTH). We used a lifetime horizon and half cycle correction (Sonnenberg and Beck 1993). We used the TreeAge Software (Tree-Age Software, Inc.) to produce and evaluate the decision model.

A screenshot of the two decision trees and Markov models are presented in Online Resource. Running the two Markov models calculate the total lifetime QALYs and total healthcare costs for an average worker undergoing each social condition of working standard hours and working more than standard hours.

\subsection{Results and discussion}

\subsubsection{QALYs and cost-effectiveness analysis}

Table 3 presents the incremental lifetime QALYs and costs per worker for the two social conditions of working standard hours and working more than standard hours. The results show that working standard hours has led to 34.69 QALYs with CAD \$495,155 cost per worker while working more than standard hours has led to 33.96 QALYs with CAD $\$ 501,857$ cost per worker (see Table 3). Therefore, working standard hours compared to more than standard hours led to an increase of 0.73 QALY and decrease in cost of $\$ 6702$ per worker. In this case, the alternative social condition of working standard hours is not associated with an incremental cost, instead it is cost saving and more effective. In the Canadian context, based on an estimated 2.4 million Canadian workers working more than standard hours, this resulted in a total gain of 1.7 million QALYs and saving of CAD $\$ 16$ billion overall if Canadian workers work standard hours rather than the current state of working more than standard hours. The results could be calculated by sector or company or product supply chain in Canada by changing the total number of workers working more than standard hours. Working standard hours is associated with more QALYs and lower costs over the lifetime mainly due to the higher chance that workers stay in the healthy state compared to working more than standard hours (see Online Resource for the distribution of QALYs per worker by each health state).

\subsubsection{Recommendations}

The results show that working standard hours is more effective and cost saving compared to working more than standard hours from the perspective of Canadian healthcare system. Discussing the results from the business' perspective may differ based on the difference between the cost of letting employees work more than standard hours and the cost of hiring new employees to replace the current condition of working more than standard hours. This discussion needs additional data collection in terms of cost of employment and the percentage of coverage that businesses are responsible for in total healthcare costs. Working more than standard hours is associated with some indirect costs on companies, caused by absenteeism of employees and lost productivity, lost workdays, under-performance, and workplace disability. While these indirect costs are considered in this study as part of overall healthcare costs, the additional data collection needed from the business perspective is outside the scope of this paper and needs additional analysis.

To propose some recommendations to reduce the negative health and resulting economic impacts of the current social condition in Canada of working more than standard hours, it is necessary to look at some background information of the reasons that workers accept to work long hours. The reasons can depend based on the context (country and sector). A study by Statistics Canada has found that workers with low job quality (no pension coverage, no stability), low wage, non-standard workers are more likely to accept working long hours, despite the higher stress and health impacts associated with that (Heisz and LaRochelle-Côté 2006) which is demonstrated in this current study. In some cases, workers 


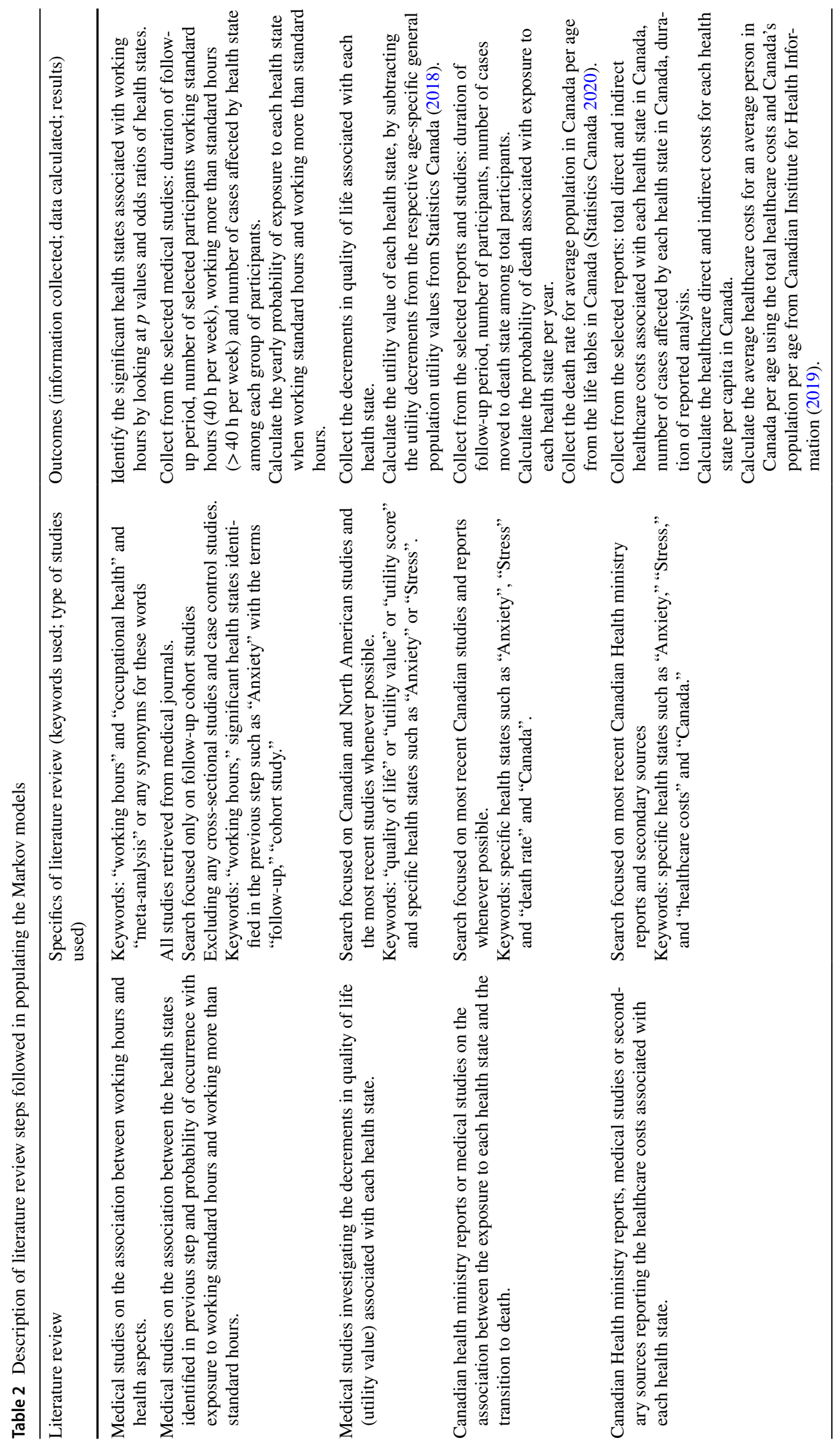




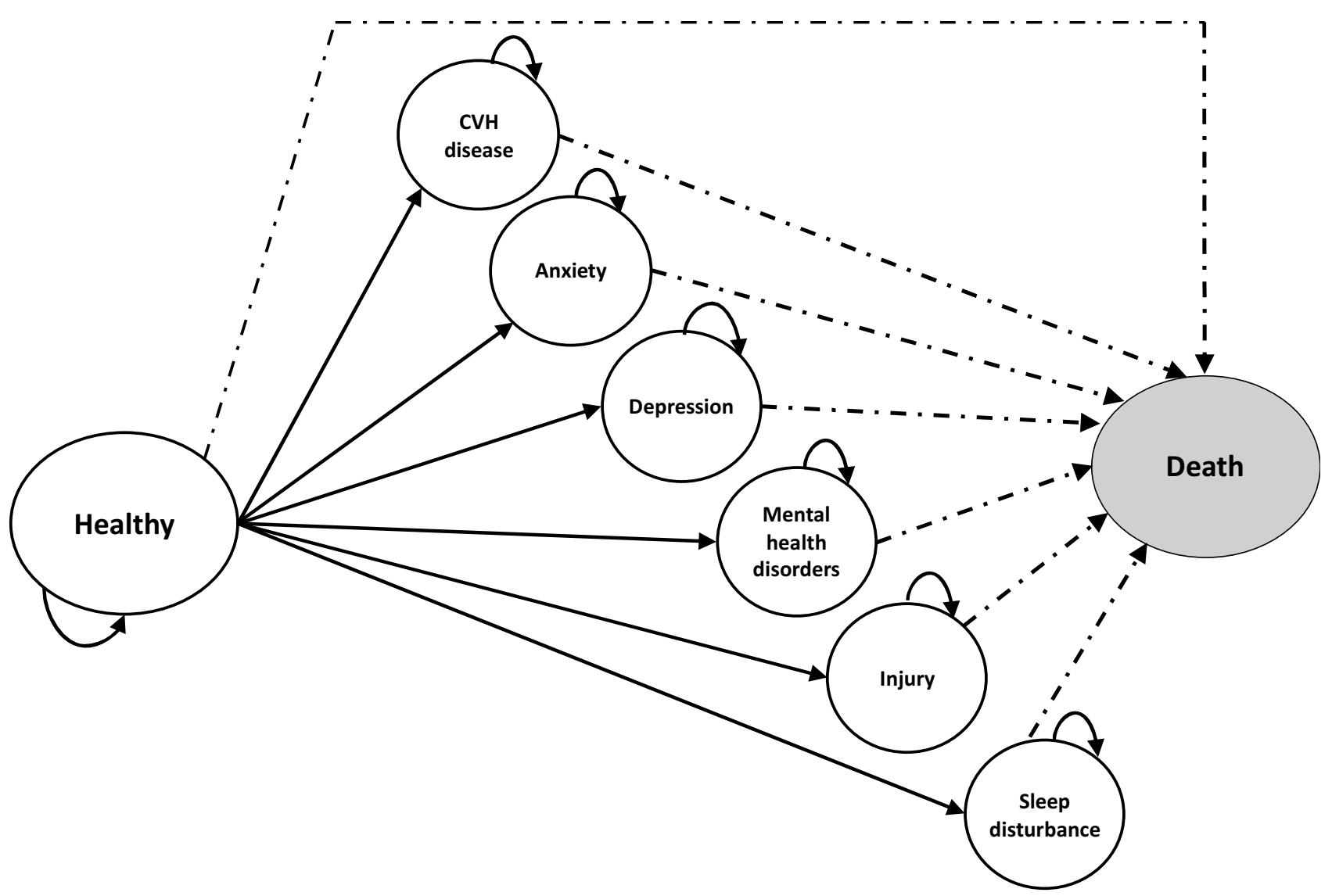

Fig. 6 Schematic representation of the two Markov models related to the two social conditions of "working standard hours" and "working more than standard hours"

have to work long hours to maintain the security of their jobs as they are not able to find other stable jobs and their employers expect them to work more than standard hours. In other cases, reasons may include financial gain and accelerate career development for a possibility of a promotion or applying for a better job. Some reasons might be more specific to the sector or industry. For example, a specific study on working overtime for critical care nurses in Canada has found additional reasons including the love of nurses for their work and their intention to help other colleagues and being with them for more social interactions, especially for those with no other life commitment, as well as their desire

Table 3 Incremental lifetime QALYs and costs per worker: working standard hours via working more standard hours

\begin{tabular}{lll}
\hline Working hours conditions & $\begin{array}{l}\text { Overall QALYs } \\
\text { (total effectiveness) }\end{array}$ & $\begin{array}{l}\text { Overall costs } \\
\text { (in Canadian } \\
\text { dollars) }\end{array}$ \\
\hline $\begin{array}{l}\text { Working standard hours } \\
\begin{array}{l}\text { Working more than standard } \\
\text { hours }\end{array}\end{array}$ & 34.69 & 495,155 \\
\hline
\end{tabular}

to create a greater sense of familiarity for patients and themselves (Lobo et al. 2018).

Starting from these reasons and based on the results presented in Sect. 3.2.1, examples of multiple entry points for intervention can be proposed at different points in the cause-effect chain using DPSIR to reduce the negative health impacts of working more than standard hours in Canada (Fig. 7). Examples vary from policy interventions, companies' actions, public awareness, and education to increased investments in more research.

\section{Discussion and conclusions}

The methodology developed in this study has first used the DPSIR framework to extend the focus of current impact pathways in type II S-LCIA beyond the downstream impacts to a systematic analysis covering connections between the root causes of social issues and the resulting impacts. The systematic and interdisciplinary characteristics of DPSIR are useful for analysing the whole story of cause-effect chains in relation to social issues in S-LCA and to identify multiple entry points for interventions along the path. We mapped 


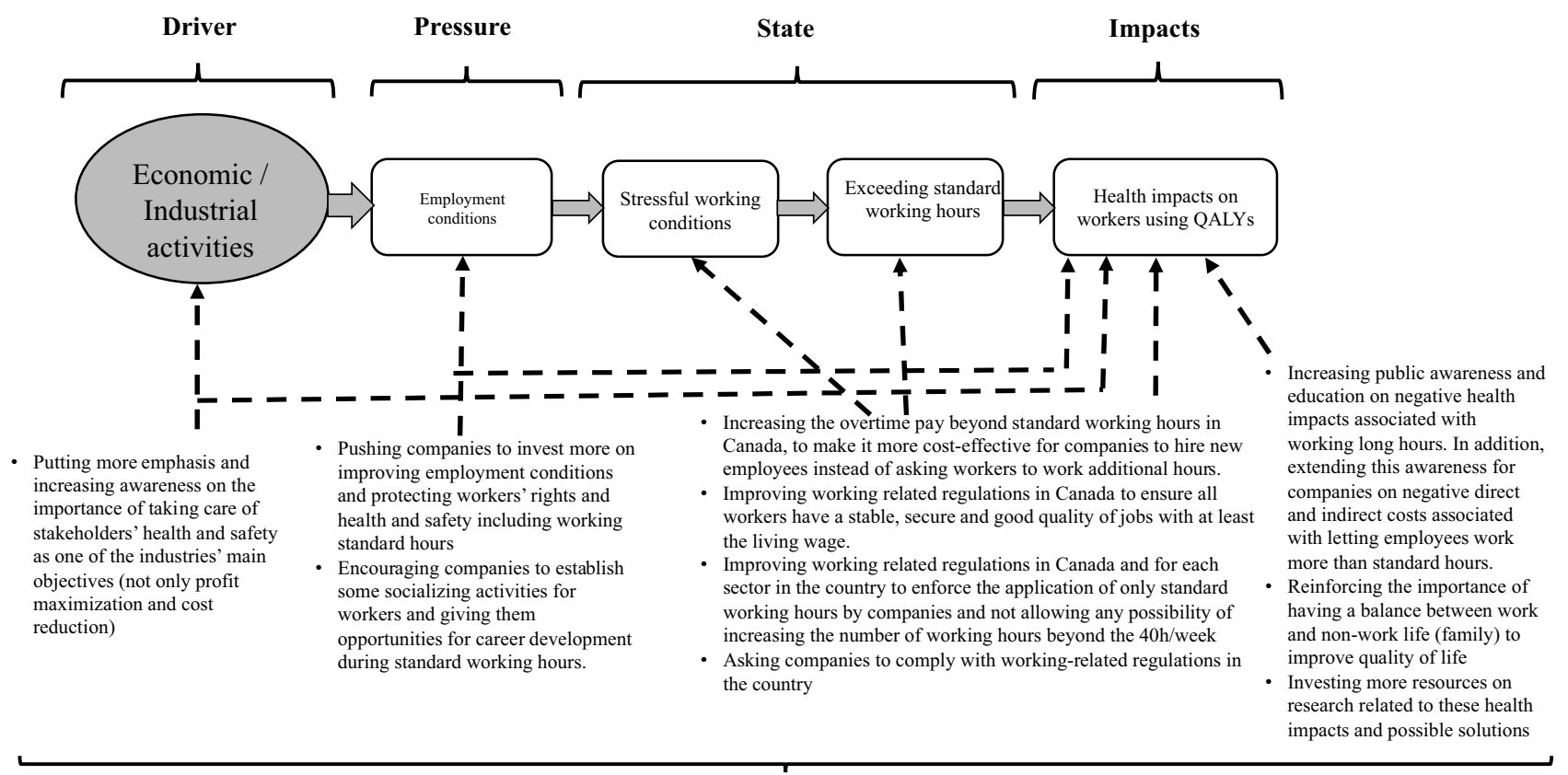

Response

Fig. 7 Examples of possible interventions at multiple points in cause-effect chain in relation to "working hours" in Canada to reduce negative health impacts of working more than standard hours

the DPSIR framework into the corresponding elements of the S-LCA context in relation to the social subcategories defined in UNEP/SETAC methodological sheets. Next, the methodology has developed a more robust impact pathway method to quantify the life-time health and economic outcomes associated with social subcategories for the first time using decision analytic models including decision trees and Markov models. This S-LCIA method goes beyond the focus of current approaches on macro-level scale social issues to tackle the same variety of social issues (i.e., subcategories) covered in type I S-LCIA. Since the impacts of these social subcategories are hard to quantify, long-term, associated with uncertainty and difficulty in data collection, decisionanalytic modeling is used in this methodology to address these aspects.

The strengths of this methodology lie in two aspects: (1) the possibility of examining the connections between the main root causes of social issues and impacts using the DPSIR framework, which is the main point in cause-effect chains of S-LCA (2) and in quantifying the lifetime health and economic consequences in relation to social subcategories in UNEP/SETAC methodological sheets based on medical literature and healthcare studies, measured in increase or decrease of QALYs translated in economic consequences. The methodology was illustrated by using the "working hours" social subcategory in Canada. A systematic analysis of the cause-effect chains in relation to this social subcategory and workers stakeholder group was conducted.
In addition, in applying the impact assessment method, we were able to quantify the incremental lifetime QALYs and economic healthcare consequences of "working hours" conditions in Canada. This quantification was conducted using decision-analytic modeling based on previous Canadian healthcare studies, health ministry reports and secondary sources. A CEA of the results has identified that working standard hours is more effective and cost-saving than the existing state of social issue for some workers in Canada of working more than standard hours. These results within the systematic DPSIR framework helped in identifying possible cost-effective interventions at multiple entry points of the cause-effect chain to improve the social performance and reduce the negative health impacts associated with the existing state of working more than standard hours in Canada.

The application of the developed method in S-LCA can map the cause-effect chains in relation to the state of social subcategories in a systematic way using DPSIR framework. This mapping can help decision-makers to understand the connections between roots and impacts of social issues identified in the inventory phase of S-LCA. In addition, the impact assessment method developed in this study quantifies the lifetime health and economic impacts of the social issues based on medical scientific evidence. This quantification can further guide decision-makers by comparing the results of current socio-economic situation to another alternative situation in relation to the social subcategory. Based on this comparison of results in the context of DPSIR 
chains, cost-effective interventions can be proposed at multiple entry points of the chains to reduce the negative impacts of socio-economic aspects in relation to the system under analysis (e.g., country, industry, company).

The further development of this impact assessment method is on-going by including more subcategories and stakeholder groups in the assessment and by applying the method on product systems. The application will be covering subcategories and stakeholder groups found relevant and in direct connections within DPSIR. This application will follow the same process implemented for "working hours" subcategory, in terms of applying the DPSIR framework and collecting data from medical health literature to run the decision analytic models and calculate QALYs. One potential challenge is that applying the methodology on other social subcategories depends on the availability of previous medical literature examining the association between social conditions related to UNEP/SETAC subcategories and health aspects in terms of probabilities of occurrence. Another challenge is related to the difficulty in finding healthcare studies for the specific geographical context of the case study, in these cases the closest studies have to be used. Even though data used to populate Markov models are estimates conducted by researchers in medical studies, however using these medical literature and healthcare evidence and approaches to assess the health and economic outcomes has reduced the uncertainty associated with the assessment of these impacts. Integrating medical health studies and decision-analytic models in S-LCA to build cause-effect chains and quantify the lifetime health and economic impacts of social issues might add some complexity to the application of S-LCA. However, this integration adds quality and relevance to how the impact assessment should be done through scientific evidence and support and thus increases the objectivity of the S-LCA approach that suffers from a lot of subjectivity and uncertainty in assessing its impacts. Therefore, complexity could be reduced by increasing the quality and relevance to how the S-LCA approach should be conducted.

To facilitate the application of the method developed here in S-LCA in the future, once the translation of social subcategories into QALYs is done, a database can be built for use by, for example, corporate decision-makers to quantify social impacts by calculating the total QALYs and healthcare costs associated with the socio-economic conditions of, for example, their product supply chain, by changing the inventory inputs such as number of workers working more than standard hours, number of workers affected by discrimination or un-safe measures. When applying this method to assess the social performance of product systems, the state of social conditions in relation to subcategories (inventory inputs) are tied to the social performance of companies responsible for the different unit processes of product systems and not to a quantified functional unit. This method has been used in Type I S-LCIA (e.g., Ramirez et al. 2014, 2016). Future work on the method may consider as well including the economic costs of implementing social conditions from the business perspective as part of CEA.

Overall, the methodological approach will help decisionmakers to establish the cause-effect aspects of the social performance of their systems of interest in a quantitative form from a life cycle perspective in line with the cause-effect relationships in E-LCA. This unification in impact pathway approaches will facilitate the implementation of LCSA. This method will potentially be used as well to identify possible interventions needed in product systems and supply chains to improve the social performance in a cost-effective way. This systematic analysis in building cause-effect chains and quantitative assessment of impacts based on medical literature and decision analytic models will serve the purpose of S-LCA in guiding decision-making to improve the social performance of product systems.

Supplementary Information The online version contains supplementary material available at https://doi.org/10.1007/s11367-021-01900-6.

Acknowledgements The authors acknowledge support from the University of Calgary's Canada First Research Excellence Fund (CFREF) program, entitled the Global Research Initiative (GRI) in Sustainable Low Carbon Unconventional Resources.

Open Access This article is licensed under a Creative Commons Attribution 4.0 International License, which permits use, sharing, adaptation, distribution and reproduction in any medium or format, as long as you give appropriate credit to the original author(s) and the source, provide a link to the Creative Commons licence, and indicate if changes were made. The images or other third party material in this article are included in the article's Creative Commons licence, unless indicated otherwise in a credit line to the material. If material is not included in the article's Creative Commons licence and your intended use is not permitted by statutory regulation or exceeds the permitted use, you will need to obtain permission directly from the copyright holder. To view a copy of this licence, visit http://creativecommons.org/licenses/by/4.0/.

\section{References}

Arvidsson R, Hildenbrand J, Baumann H, Islam KMN, Parsmo R (2018) A method for human health impact assessment in social LCA: lessons from three case studies. Int J Life Cycle Assess 23:690-699

Benoît C, Norris G, Valdivia S, Ciroth A, Moberg A, Bos U, Prakash S, Ugaya C, Beck T (2010) The guidelines for social life cycle assessment of products: just in time! Int J Life Cycle Assess $15: 156-163$

Bocoum I, Macombe C, Revéret J-P (2015) Anticipating impacts on health based on changes in income inequality caused by life cycles. Int J Life Cycle Assess 20:405-417

Canadian Institute for Health Information (2019) National Health expenditures trends 1975-2019. https://www.cihi.ca/sites/default/files/ document/nhex-trends-narrative-report-2019-en-web.pdf. Accessed 5 Aug 2020 
Clement FM, Harris A, Li JJ, Yong K, Lee KM, Manns BJ (2009) Using effectiveness and cost-effectiveness to make drug coverage decisions: a comparison of Britain, Australia, and Canada. JAMA 302(13):1437-1443. https://doi.org/10.1001/jama.2009.1409

Devlin N, Parkin D (2004) Does NICE have a cost-effectiveness threshold and what other factors influence its decisions? A binary choice analysis Health Econ 13(5):437-452

Dreyer L, Hauschild M, Schierbeck J (2006) A framework for social life cycle impact assessment. Int J Life Cycle Assess 11:88-97

Feschet P, Macombe C, Garrabé M, Loeillet D, Saez AR, Benhmad F (2012) Social impact assessment in LCA using the Preston pathway. Int J Life Cycle Assess 18:490-503

Garber AM, Phelps CE (1997) Economic foundations of cost-effectiveness analysis. J Health Econ 16(1):1-31

Gauthier C (2005) Measuring corporate social and environmental performance: the extended life-cycle assessment. J Bus Ethics 59:199-206

Government of Canada (2020) Hours of work https://www.canada.ca/en/ employment-social-development/programs/employment-standards/ work-hours.html. Accessed 20 July, 2020

Hannouf M, Assefa G (2017) Life cycle sustainability assessment for sustainability improvements: a case study on high density polyethylene production in Alberta. Canada Sustainability 9(12):2332

Hannouf M, Assefa G (2018) Subcategory assessment method for social life cycle assessment: a case study of high density polyethylene production in Alberta, Canada. Int J Life Cycle Assess 23:116-132

Heisz A, LaRochelle-Côté S (2006) Work hours instability in Canada. Statistics Canada. http://citeseerx.ist.psu.edu/viewdoc/download? doi=10.1.1.548.7230\&rep=rep1\&type=pdf. Accessed 20 July, 2020

Henry DA, Hill SR, Harris A (2005) Drug prices and value for money: the Australian pharmaceutical benefits scheme. JAMA 294(20):2630-2632

Huertas-Valdivia I, Ferrari AM, Settembre-Blundo D, Gracia-Muina FE (2020) Social life-cycle assessment: a review by bibliometric analysis. Sustainability 12:6211

Iofrida N, De Luca AI, Silveri F, Falcone G, Stillitano T, Gulisano G, Strano A (2019) Psychosocial risk factors' impact pathway for social life cycle assessment: an application to citrus life cycles in South Italy. Int J Life Cycle Assess 24:767-780

Laupacis A (2006) Economic evaluations in the Canadian common drug review. Pharmacoeconomics 24(11):1157-1162

Lobo VM, Ploeg J, Fisher A, Peachey G, Akhtar-Danesh N (2018) Critical care nurses' reasons for working or not working overtime. Crit Care Nurse 38:6

Macombe C (2013) How can one predict social effects and impacts? In: Social LCAs - Socio-Economic Effects in Value Chains, Fruitrop Thema. CIRAD/IRSTEA

Mann CJ (2003) Observational research methods. Research design II: cohort, cross sectional, and case-control studies. Emerg Med J 20:54-60

Miners AH, Martina G, Dogan F, Fischer AJ (2005) Comparing estimates of cost effectiveness submitted to the National Institute for Clinical Excellence (NICE) by different organisations: retrospective study. BMJ 330:65

Neugebauer S, Emara Y, Hellerström C, Finkbeiner M (2017) Calculation of fair wage potentials along products' life cycle - introduction of a new midpoint impact category for social life cycle assessment. J Clean Prod 143:1221-1232

Neugebauer S (2016) Enhancing life cycle sustainability assessment tiered approach and new characterization models for social life cycle assessment and life cycle costing. Technischen Universität Berlin, Berlin

O’Brien M, Doig A, Clift R (1996) Social and environmental life cycle assessment (SELCA). Int J Life Cycle Assess 1:231-237

Parent J, Cucuzzella C, Reveret J (2010) Impact assessment in SLCA: sorting the sLCIA methods according to their outcomes. Int J Life Cycle Assess 15:164-171
Petti L, Ramirez PKS, Traverso M, Ugaya CML (2016) An Italian tomato "Cuore di Bue" case study: challenges and benefits using subcategory assessment method for social life cycle assessment. Int J Life Cycle Assess. https://doi.org/10.1007/s11367-016-1175-9

Ramirez PKS, Petti L, Haberland NT, Ugaya CML (2014) Subcategory assessment method for social life cycle assessment. Part 1: methodological framework. Int J Life Cycle Assess 19:1515-1523

Ramirez PKS, Petti L, Brones F, Ugaya CML (2016) Subcategory assessment method for social life cycle assessment. Part 2: application in Natura's cocoa soap. Int J Life Cycle Assess 21:106-117

Ramos Huarachi DA, Piekarski CM, Fabio Neves Puglieri FN, Carlos de Francisco A (2020) Past and future of social life cycle assessment: historical evolution and research trends. J Clean Prod 265:121506

Siebert U (2003) When should decision-analytic modeling be used in the economic evaluation of health care? Eur Journal Health Economic 4:143-150

Smeets E, Weterings R (1999) Environmental indicators: typology and overview. Copenhagen, Denmark, European Environment Agency

Sonnenberg FA, Beck JR (1993) Markov models in medical decision making: a practical guide. Med Decis Making 13:322-338

Statistics Canada (2020) Life Tables, Canada, Provinces and Territories 1980/1982 to 2016/2018. https://www150.statcan.gc.ca/n1/pub/84537-x/84-537-x2019002-eng.htm. Accessed 5 June 2020

Statistics Canada (2018) Health Utilities Index Mark 3 Scores for Major Chronic Conditions: Population Norms for Canada Based on the 2013 and 2014 Canadian Community Health Survey. https:// www150.statcan.gc.ca/n1/pub/82-003-x/2018011/article/00001eng.htm. Accessed 10 June 2020

Statista (2020a) Total number of employed persons in Canada in 2019, by average usual weekly hours. https://www.statista.com/statistics/ 438177/employment-level-in-canada-by-average-usual-weeklyhours/. Accessed 5 June, 2020

Statista (2020b) Total number of employed persons in Canada in 2019, by age group. https://www.statista.com/statistics/437700/employmentin-canada-by-age-group/. Accessed 5 June 2020

Sureau S, Neugebauer S, Achten WMJ (2019) Different paths in social life cycle impact assessment (S-LCIA) - a classification of type II impact pathway approaches. J Life Cycle Assess Int. https://doi.org/ 10.1007/s11367-019-01693-9

Torrance GW (1986) Measurement of health state utilities for economic appraisal. J Health Econ 5(1):1-30

UNEP (2020) Guidelines for Social Life Cycle Assessment of Products and Organizations 2020. Benoît Norris C, Traverso M, Neugebauer S, Ekener E, Schaubroeck T, Russo Garrido S, Berger M, Valdivia S, Lehmann A, Finkbeiner M, Arcese G (eds) United Nations Environment Programme (UNEP)

UNEP/SETAC (2009) Guidelines for social life cycle assessment of products. United Nations Environment Program, Paris SETAC Life Cycle Initiative. http://www.unep.fr/shared/publications/pdf/DTIx1164xPAguidelines_sLCA.pdf

UNEP/SETAC (2013) The methodological sheets for sub-categories in social life cycle assessment (S-LCA). http://www.lifecycleinitiative. org/wp-content/uploads/2013/11/S-LCA_methodological_sheets_ 11.11.13.pdf

Weidema BP (2020) Towards a Taxonomy for Social Impact Pathway Indicators. In: Traverso M, Petti L, Zamagni A (eds) Perspectives on Social LCA. Springer Briefs in Environmental Science. Springer, Cham

Weidema BP (2018) The social footprint - a practical approach to comprehensive and consistent social LCA. Int J Life Cycle Assess 23:700-709

Weidema BP (2006) The integration of economic and social aspects in life cycle impact assessment. Int J Life Cycle Assess 1:89-96

Wong K, Chan AHS, Ngan SC (2019) The effect of long working hours and overtime on occupational health: a meta-analysis of evidence from 1998 to 2018. Int J Env Res Pub Health 16:2102 
Wu R, Yang D, Chen J (2014) Social life cycle assessment revisited Sustainability 6:4200-4226

Zheng X, Easa SM, Ji T, Jiang Z (2020) Modeling life-cycle social assessment in sustainable pavement management at project level. Int J Life Cycle Assess 15:1106-1118
Publisher's Note Springer Nature remains neutral with regard to jurisdictional claims in published maps and institutional affiliations.

\section{Authors and Affiliations}

\section{Marwa B. Hannouf $^{1}\left(\mathbb{D} \cdot\right.$ Getachew Assefa $^{1} \cdot$ Malek B. Hannouf $^{2} \cdot$ Ian $_{\text {Gates }}{ }^{3}$}

1 School of Architecture, Planning and Landscape, University of Calgary, 2500 University Drive NW, Calgary, AB T2N 1N4, Canada

2 Department of Medicine, Cumming School of Medicine, University of Calgary, 2500 University Drive NW, Calgary, AB T2N 1N4, Canada
3 Department of Chemical and Petroleum Engineering, University of Calgary, 2500 University Drive NW, Calgary, AB T2N 1N4, Canada 